\title{
PRE-DEFINITIVE PROSTHODONTIC TREATMENT WITH REHABILITATION DEVICES
}

\author{
Bhavna Sharma ${ }^{1}$, Ravneet Kaur ${ }^{2}$, Manjit Kumar ${ }^{3}$, Sumit Sethi ${ }^{4}$, Nikita Singh ${ }^{5}$ \\ ${ }^{1}$ Post Graduate student, Department of Prosthodontics, Bhojia Dental College and Hospital, Bhud, Baddi, Distt Solan, Himachal Pradesh. \\ ${ }^{2}$ Professor and Head, Department of Prosthodontics, Bhojia Dental College and Hospital, Bhud, Baddi, Distt Solan, Himachal Pradesh. \\ ${ }^{3}$ Professor, Department of Prosthodontics, Bhojia Dental College and Hospital, Bhud, Baddi, Distt Solan, Himachal Pradesh. \\ ${ }^{4}$ Reader, Department of Prosthodontics, Bhojia Dental College and Hospital, Bhud, Baddi, Distt Solan, Himachal Pradesh. \\ ${ }^{5}$ Post Graduate student, Department of Prosthodontics, Bhojia Dental College and Hospital, Bhud, Baddi, Distt Solan, Himachal Pradesh.
}

\section{ABSTRACT}

In prosthodontic treatment plan, decisions must be made regarding oral tissue rehabilitation and other necessary pre-prosthetic measures. The rehabilitation prostheses are very useful devices in the field of prosthodontics. It is essential that the mouth should be in an optimal state of health prior to commencing prosthetic treatment and failure to achieve this may produce an unsatisfactory treatment result. Depending on a variety of situations, the dentist may find it necessary to modify the patient's existing dentures or, occasionally, to construct a special appliance. This article deals with several preliminary (non-definitive) treatment options available along with a brief account of their rationale.

Keywords: Rehabilitation, Stents, Conditioning, Appliances.

\section{INTRODUCTION}

In prosthodontic treatment plan, early decisions must be made regarding essential oral tissue rehabilitation and other necessary pre-prosthetic measures. It is essential that the mouth should be in an optimal state of health prior to commencing prosthetic treatment and failure to achieve this may produce an unsatisfactory treatment result. While some patients may present for their first denture with underlying conditions, it is more common to find that those seeking replacement appliances are in need of preprosthetic treatment. Some treatment measures require 'rehabilitation devices'. Depending on a variety of situations, the dentist may find it necessary to modify the patient's existing dentures or, occasionally, to construct a special appliance, as the old denture may be irreversibly altered.

Corresponding Author: Bhavna Sharma Mobile: +91- 9882285081 E-mail:bhav11doc@gmail.com

Received: $2^{\text {nd }}$ Jan. 2014 Accepted: $10^{\text {th }}$ April 2014 Online: $25^{\text {th }}$ May 2014
Despite evolution in the technology to preserve the dentition there is still a need for prosthetic restoration and rehabilitation of partially edentulous and edentulous patients. The prosthetic replacement of lost teeth frequently involves surgical preparation of oral tissues to support prosthesis. This is the primary objective of preprosthetic surgery. Surgical improvement of the denture-bearing area and surrounding tissues presents an exciting and demanding challenge to clinicians. ${ }^{2}$

Although remarkable advances in surgical management of oral and facial defects have established, it is evident that major defects cannot be satisfactorily repaired by plastic surgery alone. ${ }^{3}$ The demand for maxillofacial prosthetic devices for rehabilitation of patients with congenital or acquired defects has intensified in recent years. ${ }^{4,5,6}$

Rehabilitation devices (transitional prostheses) $)^{1}$. This is a term that is used to describe those appliances which are used either as primary devices, to prepare a patient for prosthodontic treatment, or as an adjunct to surgical preprosthetic procedures.

The most commonly used of these include: 
- Stents for use following surgery,

- Stents for placement of implants,

- Conditioning appliances to desensitize patients who suffer from gagging and

- Pivots used to assess tolerance to vertical dimension increase.

\section{Stents}

Stents is a device used in a surgical procedure to keep skin graft in place. It can also be defined as "Any device or mold used to hold a skin graft in place or provide support for anastamosed structures (GPT- 8). ${ }^{\text {? }}$

\section{Surgical stents:}

Where border tissues have been subjected to surgery, such as for muscle attachment repositioning, frenal tissue excision, or a sulcus deepening procedure, a stent will be required to be used during the healing phase. The stent is made prior to surgery and is inserted immediately at the operation (Figures 1A, 1B). If this sequence is not followed, there is likely to be a marked loss of sulcus depth rendering denture base extension and consequent compromise to retention and stability of the denture. The stent must be of the form and required extent of a denture base. It is essential that the periphery of the device is highly polished, of rounded form having a minimum thickness of $2 \mathrm{~mm}$.

\section{Radiation stents ${ }^{8,9}$ :}

The radiation stents are the devices in the form of shielding devices and spacers used to:

- Direct the radiation source towards the target,

- Protect the adjacent vital tissues,

- Carry radiation from its source,

- Provide the bolus during radiotherapy and

- Recontour certain areas so that therapy can be simplified.

\section{Balloon retaining stent :}

The appliances are made with the balloons, which are filled by water which acts as a bolus. Bolus is a tissue equivalent material placed in line of radiation to provide better homogeneity and allows homogenous irradiation to the adjacent tissues. After major maxillary resection the adjacent soft and hard tissues have to be irradiated to eradicate remaining tumour cells. Since the wound is irregular and lacks homogeneity of the tissues, radiation to such type of tissues leads to development of hot spots.'

\section{Fluoride carrier stent :}

After radiotherapy, the teeth are prone for radiation caries. To prevent radiation caries, fluoride application is a must. The custom made resilient fluoride trays with a space of 0.2 to $0.5 \mathrm{~mm}$ are fabricated for the patients and provided. ${ }^{10}$

\section{Ocular conformer or ocular stent:}

These are the stents made up of silicone or acrylic resin which are used at the time of ocular enucleation and implant placement. The purpose of the ocular conformers is to prevent the wound contracture and thus maintain the patency of the eye socket. ${ }^{6}$

\section{Trismus stent:}

The trismus stent is used to provide physiotherapy for the temporomandibular joint and the muscles of mastication as a mode of treatment for trismus. The trismus may results from radiation, surgery of maxillofacial region, trauma and infection. ${ }^{11}$

\section{Stents for placement of implants}

Stents are also recommended, in the form of a surgical template, in dental implant surgery. ${ }^{1}$ Despite significant advances in devices and techniques, placing dental implants in a correct position still remains a challenge. Diagnostic casts, probing depths and panoramic radiography can lead to unpredictable results as they do not give three-dimensional (3-D) radiographic information required for correct positioning and orientation of implant (Figure 2). ${ }^{12}$ Moreover, predictable implant supported prosthesis also requires a determination of final prosthesis in treatment planning stage. Thus for a successful implant supported prosthesis the prosthodontist should plan the implant position in accordance with accurate mesiodistal and buccolingual location, angulation with residual bone and correct implant orientation. ${ }^{13}$

It has been well documented in literature that the implants placed using stents are more accurately positioned than those without the stent. Ever since the introduction of stents in implant dentistry various designs have been suggested. ${ }^{14}$ The relative advantages and disadvantages of some of them have been listed in Table 1. of radiologic science ranging from theoretical radiation physics to clinical radiologic imaging and treatment are illustrated in this article. 
Table 1:Different types of implant stents

\begin{tabular}{|c|l|l|l|}
\hline $\begin{array}{c}\text { S. } \\
\text { No. }\end{array}$ & \multicolumn{1}{|c|}{ Types of stent } & \multicolumn{1}{|c|}{ Advantage } & \multicolumn{1}{c|}{ Disadvantage } \\
\hline 1. & Clear vaccuform stent & $\begin{array}{l}\text { Quick and easy to } \\
\text { fabricate }\end{array}$ & Less accuracy \\
\hline 2. & $\begin{array}{l}\text { Self cure acrylic stent with } \\
\text { lead strips }\end{array}$ & Simple to fabricate & $\begin{array}{l}\text { Only an immaging stent and } \\
\text { not a surgical stent }\end{array}$ \\
\hline 3. & $\begin{array}{l}\text { Self cure acrylic with metal } \\
\text { sleeves and disks }\end{array}$ & Most accurate & Expensive \\
\hline 4 & $\begin{array}{l}\text { Self cure acrylic with } \\
\text { channel filled with gutta } \\
\text { percha }\end{array}$ & $\begin{array}{l}\text { Acceptable accuracy, } \\
\text { easy to fabricate and } \\
\text { inexpensive }\end{array}$ & $\begin{array}{l}\text { Not as accurate as } \\
\text { compared to metal sleeves } \\
\text { and disks }\end{array}$ \\
\hline
\end{tabular}

The technique of combined use of prosthodontic stents and 3D imaging is an efficacious and better technique in achieving the ideal position of dental implants as compared to the conventional technique of using periapical and panoramic radiographs or casts. The only care that needs to be taken is in the conversion of the stent from radiographic to surgical use. It should be taken into consideration that there may be a discrepancy between the angulation and position of the radio-opaque marker and ideal implant location. ${ }^{15}$

\section{Conditioning appliances}

A conditioning appliance, or training plate, may be provided for home use for a patient who suffers from nausea or gagging when wearing a denture. The most common causes of gagging are looseness/rocking of the denture, excessive thickness of the posterior border of the upper denture (particularly when it is placed forward of the vibrating line), or a narrow arch form that forces the lingual cusps of the upper posterior teeth to impinge on the dorsum of the tongue.

As it seems to be a psychological or behavioral problem, by taking patient in full confidence, a training plate can be helpful to overcome such a problem. The training plate must be fully extended and properly tapered in thickness at the posterior border that must be provided with a carefully formed post dam. A finger grip may be provided so that the patient can control insertion and removal of the device (Figures 3A, 3B). Additionally, psychological assessment might be appropriate for some patients, in association with some adaptational/self-controlling measures such as autohypnosis and controlled breathing. ${ }^{1}$

\section{Occlusal pivot appliances}

Where excessive freeway space is present with existing dentures, it is not advisable to increase the denture height beyond some $3 \mathrm{~mm}$ at a time unless the tolerance of the patient to a greater increase is first determined. This can be achieved by the use of occlusal pivots.

Occlusal pivots consist of two flat-surfaced pillars of acrylic resin placed bilaterally in the second premolar and first molar region of the lower denture (Figure 4A). These planes must contact the opposing teeth of the upper denture bilaterally and evenly. Pivots can also be used where a gross error in the retruded contact position (RCP) of occlusion is present, to increase the stability of the denture bases and thus reduce trauma to the underlying tissues

Pivots are made using thin tin foil placed on a paste of self-polymerising polymer (methyl methacrylate) (PMMA) added to the occlusal surfaces of the second premolar/first molar region of the lower denture (Figure 4B). The denture is seated in the mouth and the patient instructed to close gently into RCP. Closure must cease when bilateral contact is made to prevent displacement of the acrylic dough. The denture is then removed from the mouth and the PMMA cured, after which the occlusal contacts are confirmed as simultaneously bilateral and at the required occlusal vertical dimension. The tin foil is then removed and the occlusal pivots are polished with the occlusal surfaces made flat. ${ }^{1}$ 

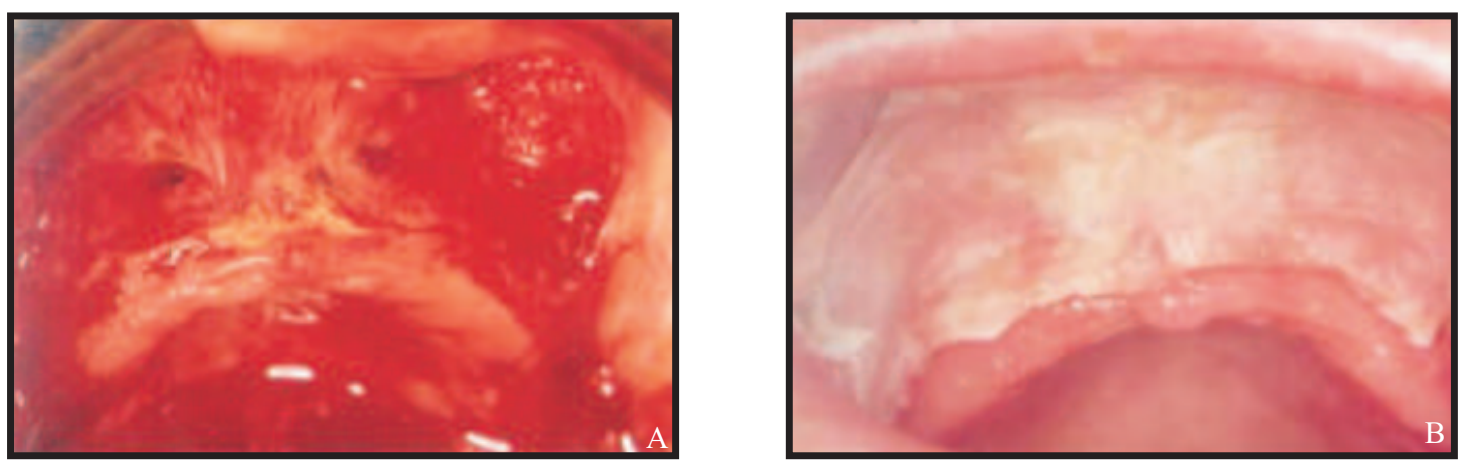

Figure 1(A, B) : Surgical stent placed after vestibuloplasty
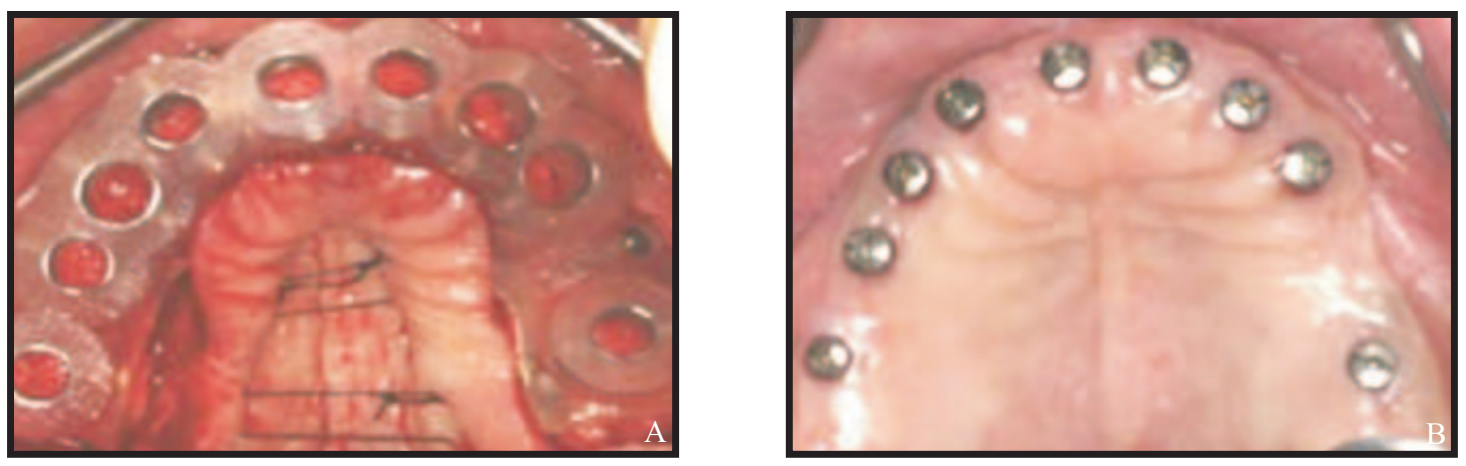

Figure 2 (A, B) : Radiographic stent for implant placement
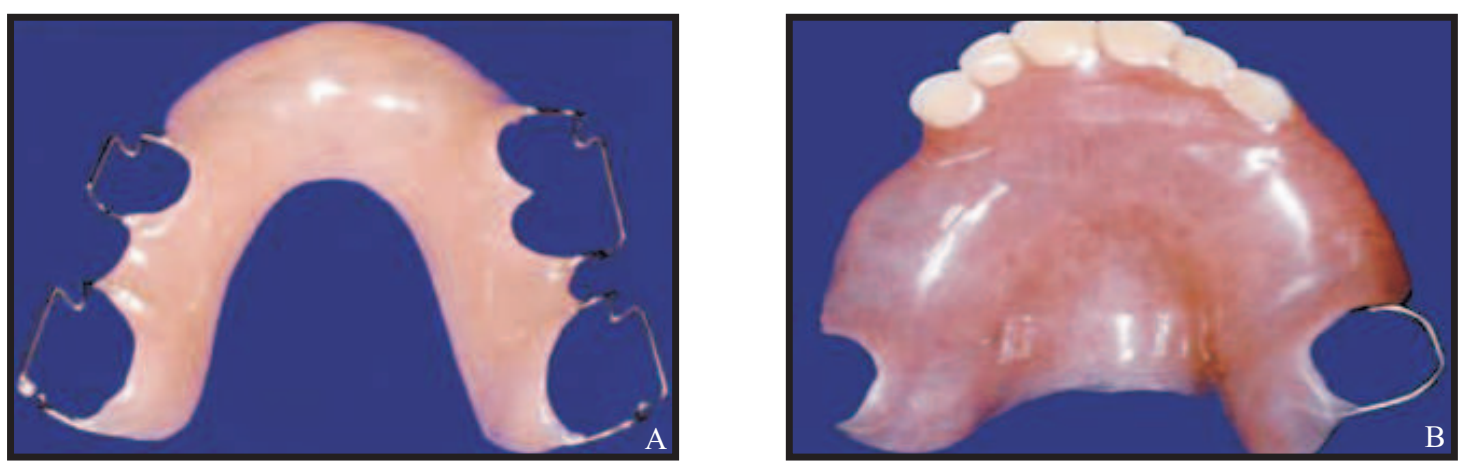

Figure $3(\mathrm{~A}, \mathrm{~B})$ : Training Denture
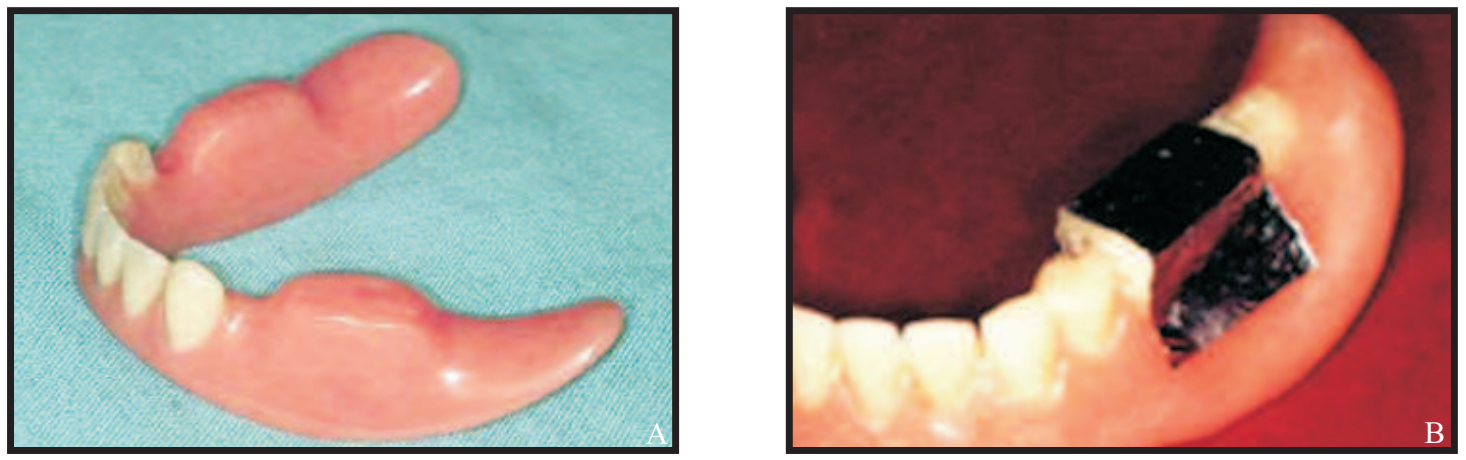

Figure 4 (A, B): Occlusal Pivot Appliance 


\section{CONCLUSION}

The rehabilitation prostheses are very useful devices in the field of prosthodontics. Judicious use of these devices minimizes severity of the problems, improves the prognosis and provides comfort to the patient. The stents are excellent examples for preventive prosthodontic devices in the field of maxillofacial prosthetics. Although most general dental practitioners might not be normally expected to make such prostheses, they should be aware of the fact that they may be requested to make one by an oral surgeon, to whom they have referred a patient. These stents for either soft tissue management or implant placement should be planned by the clinician providing the restorative care prior to surgery.

\section{REFERENCES}

1. McCord J.F, Grant A.A. Pre-definitive treatment: rehabilitation prostheses. Br Dent J 2000; 188(8): 419-24.

2. Berg R.W, Goldman B.M. Kurtz K, Schweitzer K, Kraut R.A. Prosthodontic management of sulcoplasty and sialodochoplasty with a conforming surgical stent. J of Prosthodont 2008; 17: 52-54.

3. Laney W.R, Salinas T.J. Diagnosis and Treatment in
Prosthodontics. 2nd ed. Quintissence Pub Co 2011.

4. Chalian V.A., Drane J.B, Standish S.M. Maxillofacial prosthetics: Multidisciplinary Practice. Williams and Wilkins Pub Co. 1972.

5. Laney W.R, Chalian V.R. Maxillofacial Prosthetics. Postgraduate Dental handbook Series. Volume 4. PSG Pub. Co 1979.

6. Beumer J, Curtis T.A, Marunick M.T. Maxillofacial Rehabilitation: Prosthodontic \& Surgical Cosiderations. ST. Louis: Elsevier 1996.

7. Glossary of Prosthodontic Terms- 8.

8. Correng J. Fleming. Tongue Shielding Radiation Stent. J Prosthet Dent 1983; 49: 389-92.

9. R. Miyamoto et al. Radiotherapy by Using Balloon Retaining Stent. J Prosthet Dent 1992; 68:115-17.

10. Arturo Santiago. Role of Dentist in Radiotherapy. J Prosthet Dent 1973; 30:196-201.

11. Harry C. Lundeen, Charles H. Gibbs. Advances in Occlusion.

12. Almong DM, Torrado E, Meitner SW Fabrication of imaging and surgical guides for dental implants. J Prosthet Dent 2001; 85:504-08.

13. Garber DA The esthetic dental implant: letting restoration be the guide. J Am Dent Assoc 1995; 126:319-25.

14. Talwar N, Singh B.P, Chand P. Use of Diagnostic and Surgical Stent: A Simplified Approach for Implant Placement. J Indian Prosthodont Soc 2010; 10(4):234-39.

15. Talwar N, Singh B.P, Chand P. Evaluation of the Efficacy of a Prosthodontic Stent in Determining the Position of Dental Implants. J of Prosthodont 2012;21:42-47.

Source of Support: Nil, Conflict of Interest: None Declared 